\title{
Modulus of Natural Rubber Cross-Linked by Dicumyl Peroxide. I. Experimental Observations
}

\author{
Lawrence A. Wood \\ Institute for Materials Research, National Bureau of Standards, Washington, D.C. 20234 \\ and \\ George W. Bullman and George E. Decker \\ Institute for Applied Technology, National Bureau of Standards, Washington, D.C. 20234
}

(October 6, 1971)

\begin{abstract}
Natural rubber mixed with varying amounts of dicumyl peroxide was cross-linked by heating $120 \mathrm{~min}$ at $149{ }^{\circ} \mathrm{C}$. The quantitative measure of cross-linking was taken as the amount $f p$ of decomposed dicumyl peroxide, the product of $p$, the number of parts added per hundred of rubber and $f$ the fraction decomposed during the time of cure. The shear creep modulus $G$ was calculated from measurements of the indentation of a flat rubber sheet by a rigid sphere. The glass transition temperature $T_{g}$, was raised about $1.2{ }^{\circ} \mathrm{C}$ for each part of decomposed dicumyl peroxide. Above $\left(T_{g}+12\right)$ the modulus-temperature relations were linear with a slope that increased with increasing cross-linking. The creep rate was negligible except near the glass transition and at low values of $f p$. Values of $G$, read from these plots at seven temperatures, were plotted as a function of $f p$. The linearity of the two plots permits the derivation of the general relation: $G=S(f p+B) T+H(f p+B)+A$ where $A, B, H$, and $S$ are constants. The lines representing $G$ as a function of $f p$ at each temperature all intersected near the point, $f p=0.45 \mathrm{phr}, G=2.70 \mathrm{Mdyn} \mathrm{cm}^{-2}\left(0.270 \mathrm{MN} \mathrm{m}{ }^{-2}\right)$. The constants were evaluated as

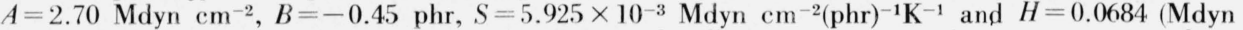
$\left.\mathrm{cm}^{-2}\right)(\mathrm{phr})^{-1}$. This equation represented satisfactorily all the data obtained at temperatures from -50 to $+100{ }^{\circ} \mathrm{C}$ for values of $f p$ from about 1 to $24 \mathrm{phr}$.
\end{abstract}

Key words: Creep; cross-linking; dicumyl peroxide; glass transition; indentation measurements; rubber, natural.

\section{Introduction}

Studies of the modulus of natural rubber are conveniently made by observing the indentation of a flat rubber sheet by a rigid sphere. In previous investigations $[1,2]^{1}$ in our laboratory we have studied the compliance (reciprocal of the modulus) as a function of time and temperature for pure-gum vulcanizates of natural and synthetic rubbers cross-linked by conventional sulfur-accelerator curing systems. In the present work similar studies were made for natural rubber which had been cross-linked by varying amounts of dicumyl peroxide. The results obtained with this system should be of fundamental significance, since the amount of cross-linking can be evaluated quantitatively and the cross-links are considered to be direct carbon-carbon bonds. Time effects have been found to be negligible over much of the ranges of temperature and cross-linking investigated [3, 4].

\footnotetext{
${ }^{1}$ Figures in brackets indicate the literature references at the end of this paper.
}

\section{Decomposition of Dicumyl Peroxide}

Peroxides have been recognized as cross-linking agents for rubber for more than fifty years. Recent work has been concentrated on dicumyl peroxide, which is particularly suitable because of favorable values of volatility and reaction rate at various temperatures. Used without any. auxiliary materials it is especially convenient for fundamental studies.

The mechanism of cross-linking of elastomers by dicumyl peroxide has been extensively studied in recent years. The results are outlined in a comprehensive review by Loan [5]. The basic mechanism is particularly simple in the case of natural rubber. At elevated temperatures the peroxide splits, by a first-order reaction, into two free radicals each of which is neutralized by the removal of a hydrogen atom from the rubber. Carbon-carbon primary valence bonds between different rubber molecules are then formed at the sites from which the hydrogen atoms have been removed. In the absence of side reactions, 
each peroxide molecule decomposed thus is responsible for the formation of one cross-link. The rate of the reaction is controlled by the rate of decomposition of the peroxide. The reaction products (other than the cross-linked rubber, of course) are $\alpha$ - $\alpha^{\prime}$-dimethyl benzyl alcohol, acetophenone, and methane. The methane would be expected to pass through the rubber and be lost at the temperature of vulcanization. Although this temperature is below the boiling points of the other two products, their vapor pressures at this temperature are quite high. Consequently it is expected that a considerable portion of them will be evaporated, with the residue remaining in the rubber. Since they are an alcohol and a ketone they would not be expected to swell the rubber or to dissolve in it to any appreciable extent.

The fraction $f$ of molecules decomposed in a firstorder reaction in a given time $t$ can be shown to be such that

$$
\log _{10}(1-f)=-0.3010\left(t / t_{1 / 2}\right)
$$

where $t_{1 / 2}$ is the half-life, the time required for half of the molecules to decompose. The equation shows that for increasing values of $t, f$ is an increasing function of decreasing slope, rising from zero to reach a value of 0.95 at $t / t_{1 / 2}=4.3$. It approaches a value of unity at infinite time, of course.

The variation of a first-order reaction rate with temperature is most conveniently represented by a plot of $\log t_{1 / 2}$ against $-T^{-1}$, the reciprocal of the temperature in kelvins, as in figure 1. This plot yields a straight line represented by

$$
\log t_{1 / 2}=(\Delta H / 2.30 R)\left(T^{-1}-T_{1}^{-1}\right)
$$

where $\Delta H$ is the activation energy of the reaction, $R$ the gas constant, and $T_{1}$ the value of the temperature at which $t_{1 / 2}=1 \mathrm{~min}$.

The observations represented in figure 1 were obtained by Hummel and co-workers [6], who measured the amount of unreacted dicumyl peroxide in natural rubber by chemical means after varying times at elevated temperatures. The results are well represented by the straight line shown, which has the equation

$$
\log t_{1 / 2}=7800 T^{-1}-17.040 \text {. }
$$

This equation has a siope corresponding to an activation energy of 35.7 kcal mol-1 (149.4 kJ mol-1), a reasonable value for the decomposition of a peroxide. The half-life calculated from eq (1.3) is several thousand years at $25^{\circ}$, about 5 days at $100^{\circ}$, and about $27.4 \mathrm{~min}$ at $149^{\circ}$. The reaction rate is influenced relatively little by the medium in which the decomposition takes place, unless the medium is acidic.

\section{Experimental Arrangements}

In the present work pale crepe natural rubber ${ }^{2}$ was mixed with varying amounts of "recrystallized"

\footnotetext{
${ }^{2}$ NBS Standard Reference Material 385b Specific volume at $25^{\circ}, 1.1074 \mathrm{~cm}^{3} \mathrm{~g}^{-1}$.
}

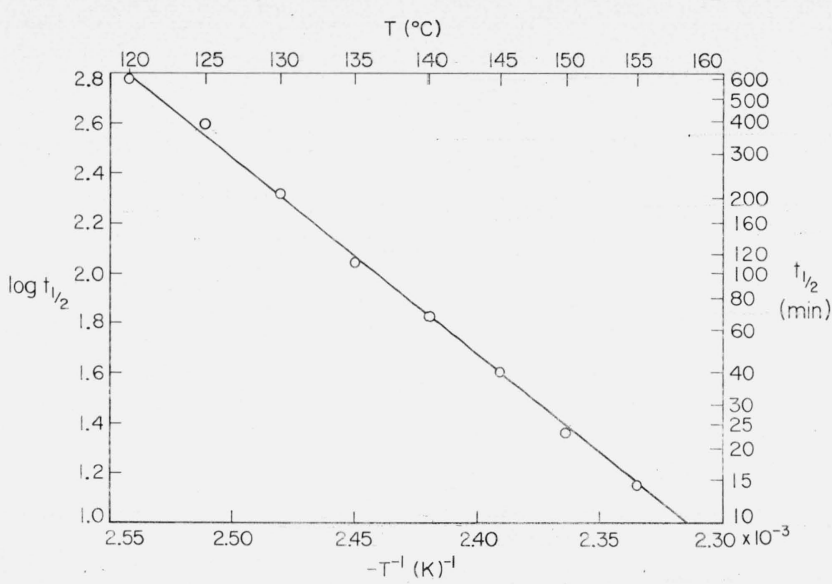

FIGURE 1. Logarithm of the half-life of dicumyl peroxide (in minutes) as a function of the reciprocal of the temperature (in kelvins).

Experimental points from data of Hummel, Scheele, and Hillmer [6] table 3, column 2. The slope of the straight line corresponds to a constant activation energy $\Delta H$ of 35.7 kcal $(\mathrm{mol})^{-1}\left(149.4 \mathrm{~kJ}(\mathrm{~mol})^{-1}\right)$.

dicumyl peroxide and cured for $120 \mathrm{~min}$ at $149{ }^{\circ} \mathrm{C}$ to form disk specimens about $35 \mathrm{~mm}$ in diameter and 9 $\mathrm{mm}$ in thickness. The amounts, $p$, of dicumyl peroxide added to each 100 parts by weight of rubber were $0,0.5,1,2,3,4,5,7,8,10,15,20$, and 25 parts respectively. Larger amounts of dicumyl peroxide yielded specimens which were too brittle for satisfactory handling. The results discussed in the preceding section would indicate that at $149{ }^{\circ} \mathrm{C}$ the half-life $t_{1 / 2}$ is about $27.4 \mathrm{~min}$, as already stated. Consequently, from eq $(1.1)$, at $120 \mathrm{~min}\left(=4.38 t_{1 / 2}\right)$ about 95.2 percent of the dicumyl peroxide should have been decomposed, $(f=0.952)$. The amounts of decomposed dicumyl peroxide $f p$ are therefore calculated as $0,0.48,0.95,1.90,2.86,3.81,4.76,6.66,7.62,9.52$, $14.28,19.0$ and $23.8 \mathrm{phr}$ respectively.

The shear creep modulus $G$ (limit of the ratio of shear stress to strain at zero deformation) was calculated for each specimen from observations of the indentation of the flat rubber surface by a rigid sphere under constant load. Details of the operation of the instrument are given in two previous papers [1,2].

A linear transducer was used to measure the displacement of a ball indentor $2.50 \mathrm{~mm}$ in diameter as the load was increased from 30 to $580 \mathrm{~g}$, in most of the present work, in accordance with the procedures described in ASTM Method D 1415-56T-International Hardness of Vulcanized Natural and Synethic Rubbers. For rubbers with a low modulus, measurements were made as the load was increased from 30 to $130 \mathrm{~g}$. The indention values were never greater than the radius of the ball $(1.25 \mathrm{~mm})$.

A chamber surrounding the specimens was used to maintain any constant temperature in the range from -100 to $+100^{\circ} \mathrm{C}$ by the evaporation of liquid nitrogen. In order to avoid modulus changes arising from possible changes in crystallinity of the rubber, no observations (with two exceptions) were made between -30 and $+20{ }^{\circ} \mathrm{C}$, the region most favorable for crystalliza- 
tion. Observations were normally made over the range from 5 to $600 \mathrm{~s}$ after the application of the load.

\section{Calculation of Compliance and Modulus}

The penetration $P$ of a rigid ball of radius $R$ in contact with a plane rubber specimen of shear compliance $J$, when a force $F$ is applied, is given by the Hertz equation $[7,8]$,

$$
\frac{P}{R}=\left(\frac{3 J}{16 R^{2}}\right)^{2 / 3} F^{2 / 3}
$$

when the ratio $\frac{P}{R}$ is sufficiently small (normally less than unity). When the load is increased from a value $F_{1}$ to a value $F_{2}$ the displacement $\Delta P$ of the indentor is

$$
\left(\frac{\Delta P}{R}\right)=\left(\frac{3 J}{16 R^{2}}\right)^{2 / 3}\left(F_{2}^{2 / 3}-F_{1}^{2 / 3}\right) .
$$

This in turn gives

$$
J=\frac{16 R^{2}}{3\left[F_{2}^{2 / 3}-F_{1}^{2 / 3}\right]^{3 / 2}}\left(\frac{\Delta P}{R}\right)^{3 / 2} .
$$

The shear modulus $G$ can be calculated as equal to $J^{-1}$, since the creep rate is low or zero in all the significant portions of the present study.

For a load increase from 30 to $580 \mathrm{~g}$ on a $2.50 \mathrm{~mm}$ ball, the values of the compliance $J$ in $\mathrm{Mdyn}^{-1} \mathrm{~cm}^{2}$ $\left(10 \mathrm{MN}^{-1} \mathrm{~m}^{2}\right.$ ) and the modulus $G$ in Mdyn $\mathrm{cm}^{-2}$ $\left(0.1 \mathrm{MN} \mathrm{m}^{-2}\right)$ are:

and

$$
J=0.1833(\Delta P / R)^{3 / 2}
$$

$$
G=5.455(\Delta P / R)^{-3 / 2} \text {. }
$$

For a load increase from 30 to $130 \mathrm{~g}$ on a $2.50 \mathrm{~mm}$ ball the values of $J$ in $\mathrm{Mdyn}^{-1} \mathrm{~cm}^{2}$ and the modulus $G$ in Mdyn $\mathrm{cm}^{-2}$ are:

$$
J=1.327(\Delta P / R)^{3 / 2}
$$

and

$$
G=0.7536(\Delta P / R)^{-3 / 2} .
$$

In the derivation of the Hertz equation an expansion in terms of a series of powers of $P / R$ is followed by the neglect of all terms higher than the first. Consequently the validity of the equation is impaired when the penetration is large. Deviations can be detected experimentally when the ratio $P / R$ is greater than $0.5[1,9,10]$, but were not considered large enough to be disturbing in the present work until $P / R$ exceeded unity, near which point there is a significant change in the geometry of the system.

Equation (3.1) shows that if this condition is to be fulfilled, the $130 \mathrm{~g}$ load should not be used for specimens with $J$ greater than about $0.66 \mathrm{Mdyn}^{-1} \mathrm{~cm}^{2}$, i.e., a modulus $G$ less than $1.53 \mathrm{Mdyn} \mathrm{cm}^{-2}$. Correspondingly the $580 \mathrm{~g}$ load should not be used for specimens with $J$ greater than $0.147 \mathrm{Mdyn}^{-1} \mathrm{~cm}^{2}$,

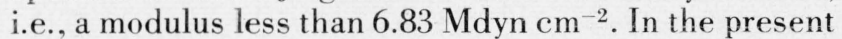
work there were no speci-ens with a modulus less than $1.53 \mathrm{Mdyn} \mathrm{cm}^{-2}$. The $130 \mathrm{~g}$ load was used for specimens with a modulus above this value. In view of the decreased sensitivity of the measurement with this load for specimens with a modulus above 6.83 Mdyn $\mathrm{cm}^{-2}$, most of the work at all higher values utilized the $580 \mathrm{~g}$ load. Where both loads were used on the same specimen the values of the calculated modulus showed good agreement.

An empirical equation with slightly different values of the constant and the exponents has been developed by Scott [11] and used in connection with hardness measurements at higher penetrations. In common with other observers $[10]$ we find that the difference between values obtained with the two equations is not sufficient to justify the use of Scott's equation over the range of penetrations we employed.

In our work it was found convenient to draw up a table showing values of $(\Delta P / R)^{3 / 2}$ for $\Delta P / R$ between 0 and 1. This facilitated the use of eq (3.4) and (3.5) to obtain values of $J$ or $G$ from experimental observations of the displacement $\Delta P$.

When the ball is pressed against the rubber sheet, some portions of the rubber are stretched, while other portions are compressed. We assume that the deformations in both cases are less than 5 percent and therefore fall within the limits of an almost linear stress-strain relation. In other words the ratio of stress to strain over this range is constant within the limits of precision of the experiment. Thus the values calculated require no further extrapolation to the limit of zero deformation as required by the definitions of compliance and modulus.

The thickness of the specimens $(9 \mathrm{~mm})$ was sufficiently large so that corrections of the type described by $W$ aters $[12,13]$ were not required.

\section{Observations}

The isochronal shear modulus $G$, measured $10 \mathrm{~min}$ after the application of the load, is plotted as a function of temperature $T$ in figure 2 for the lower values of $f p$, and straight lines are drawn to represent these values. Near the lowest temperatures a decrease of temperature causes a drastic increase of modulus. This effect is caused by an approach to the glass transition temperature and will be discussed in a later section of this paper. With the exception of that section, the present paper will concentrate attention on the modulus above these temperatures.

Where the values of $G$ at $5 \mathrm{~s}$ differ from those found at $10 \mathrm{~min}$, they are plotted as separate points (downward-pointing V's), except for temperatures below $-50^{\circ}$ (where the $5 \mathrm{~s}$ values are omitted to avoid confusion). It is seen that creep can be observed at the lowest temperatures in all cases, and at all temperatures when $f p$ is small. The reliability of the observations for the specimens containing no dicumyl peroxide $(f p=0)$ was somewhat doubtful. Consequently in this case only the observations at the lowest temperatures 


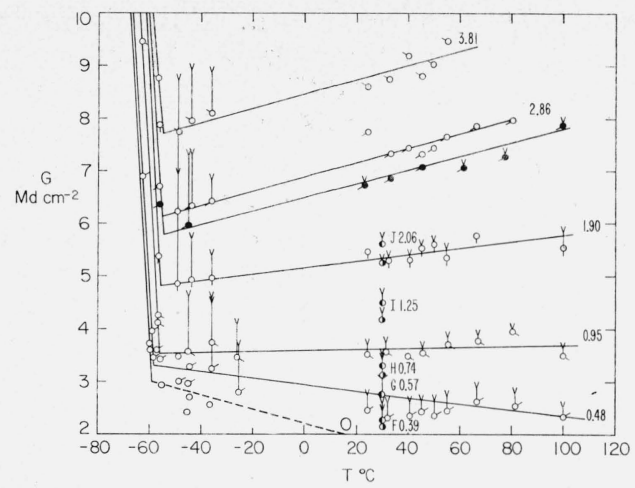

Figure 2. Shear modulus (Mdyn $\mathrm{cm}^{-2}$ or $0.1 \mathrm{MNm}^{-2}$ ) as a function of temperature.

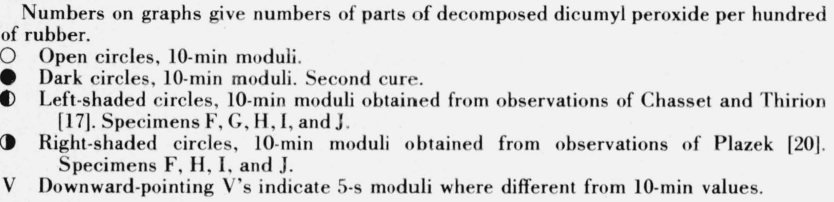

are plotted. The straight line for $f p=0$ has been drawn to pass through the value $1.88 \mathrm{Mdyn} \mathrm{cm}^{-2}$ at $25^{\circ} \mathrm{C}$ in conformity with an extrapolation mentioned later in this paper.

The observations shown in figure 2 have already been reported at the 1968 Kuala Lumpur International Rubber Conference in a paper [3] devoted to a discussion of the creep of natural rubber vulcanizates. The conclusion of the paper was that, for temperatures $40^{\circ}$ or more above the glass transition temperature, the creep rate at times greater than $5 \mathrm{~s}$ decreased with increasing cross-linking, reaching a value of the order of 0.5 percent per decade for vulcanizates cured with 2.86 parts of decomposed dicumyl peroxide.

The sensitivity of the present experimental arrangement was not sufficient to permit measurement of lower values of creep over a 2-decade range of time. For vulcanizates cured with larger amounts-from 3.81 to 23.8 parts - the indentation at $10 \mathrm{~min}$ was the same as that at $5 \mathrm{~s}$, except near the glass transition.

In later work [4] involving strips of rubber stretched to an elongation of 25-100 percent, observations extending over 4 decades of time beyond $30 \mathrm{~s}$ showed that the creep rate at room temperature was about 0.5 percent per decade for rubber cross-linked with $2.86 \mathrm{phr}$ of decomposed dicumyl peroxide, decreased to about 0.2 percent per decade for $3.81 \mathrm{phr}$, and became less than 0.03 percent per decade for $4.76 \mathrm{phr}$ or larger amounts.

In the remainder of the present paper little weight will be given to observations where the creep was appreciable, and the remaining conclusions will be based on observations where the creep between $5 \mathrm{~s}$ and $10 \mathrm{~min}$ was less than the uncertainty of measurement.

Figure 3 shows the shear modulus $G$ as a function of temperature for the higher values of $f p$. For all the observations in figure 3 , there was no measurable creep.

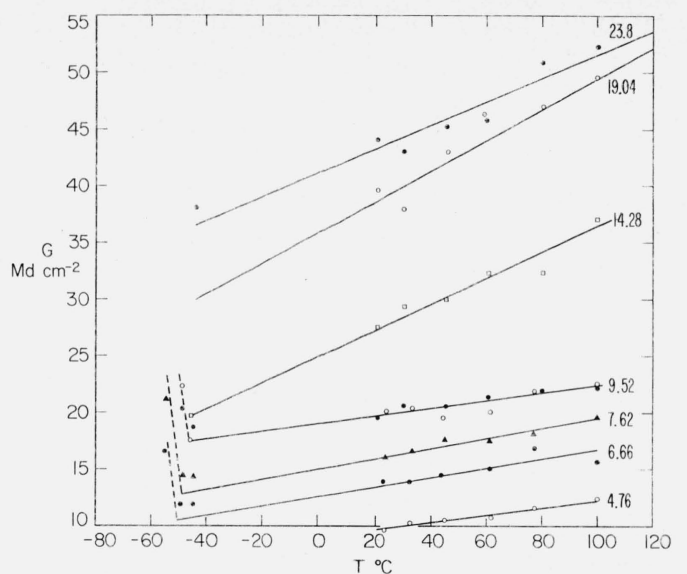

FiguRE 3. Shear modulus (Mdyn $\mathrm{cm}^{-2}$ or $0.1 \mathrm{MNm}^{-2}$ ) as a function of temperature.

Numbers on graphs give numbers of parts of decomposed dicumyl peroxide per hundred of rubber.

It will be noted that the data in figure 3 show much greater scatter for the three values of $f p$ greater than 10. However, in figure 3 and in figures shown later there is no systematic trend differing from the behavior shown for lower values of $f p$. It might well be desirable in future work to investigate this region more carefully.

In the remainder of the present paper it will be assumed that the straight lines in figures 2 and 3 give an adequate representation of the modulus data, and the conclusions will be based on the lines themselves, rather than on the individual points determining the lines.

\section{Glass Transition Temperatures}

At low temperatures, figures 2 and 3 show a sudden change of the usually positive slope of the isochronal $G, T$ curves to large negative values. The temperature at which this discontinuity of slope occurs is about $-58^{\circ}$ for the rubber containing no dicumyl peroxide and increases with increasing values of $f p$.

This effect, first noted in the stress-temperature relations by Meyer and Ferri [14], and later studied by Witte and Anthony [15] is related to the glass transition. Its exact location depends on the duration of application of the stress, lower values being obtained for longer times. For the 10-min moduli measured here $T_{d}$ the temperature of the discontinuity is about $12^{\circ}$ above the glass transition temperature $T_{g}$, as normally measured by volume-temperature relations.

Figure 4 shows a plot of the glass transition temperature $T_{g}$ (calculated as $12^{\circ}$ lower than the temperature of the discontinuity) for comparison with values determined directly from volume-temperature relations as reported by Mason [16]. Comparison is also made with values of $T_{g}$ calculated as $2^{\circ}$ lower than $T_{a}$, the temperature at which the product of the 1-minute compliance and the temperature $T$ (in kelvins) first reaches the value $0.5 \mathrm{Mdyn}^{-1} \mathrm{~cm}^{2}(\mathrm{~K})$ as the temperature is increased from very low values. The latter quantity has 


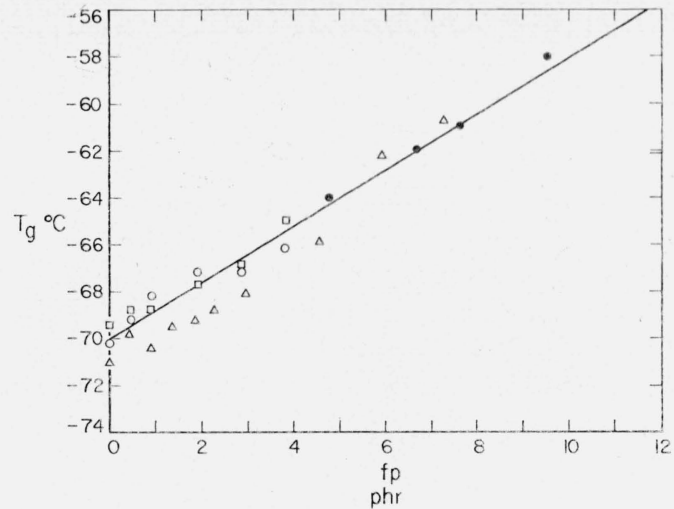

FIGURE 4. Glass transition temperature as a function of decomposed dicumyl peroxide content.

Read from figure 2 on assumption that $T_{g}=T_{d}-12$ where $T_{d}$ is the temperature of the quasi-discontinuity in the modulus-temperature relation.

Read from a plot similar to figures 2 and 3 on assumption that $T_{g}=T_{d}-12$

Calculated as $T_{g}=T_{a}-2$ where $T_{a}$ is the temperature at which the product of the l-min compliance $J$ and the temperature $T$ in kelvins first reaches the value 0.5 $\mathrm{Mdyn}^{-1} \mathrm{~cm}^{2}(\mathrm{~K})$ as the temperature is increased from very low values.

$\triangle$ Values reported by Mason [16] from direct observations of the volume-temperature relation.

The straight line represents the equation $T_{g}=-70+1.2 \mathrm{fp}$.

been used to obtain an approximation of $T_{g}$ in previous work $[3,4]$. The values of $T_{g}$ appear to be in satisfactory agreement and show a linear increase with cross-linking as measured by $f p$, the amount of decomposed dicumyl peroxide. The glass transition temperature increases at the rate of about $1.2^{\circ}$ for each part of dicumyl peroxide decomposed per 100 parts of rubber. The value of $f$, the fraction decomposed, was calculated from eqs (1.1) and (1.2). In the present work its value, as already indicated, was 0.952 , while in the work of Mason, whose vulcanizates were cured $1 \mathrm{~h}$ at $1400^{\circ} \mathrm{C}$, the value was calculated as 0.455 .

\section{Calculated Results}

In order to determine how the modulus at a given temperature varies with cross-linking, the values of the
10 -min modulus $G$ were read from the straight lines in figures 2 and 3 at 7 temperatures: $-50,-25,0,25,50$, 75 , and $100{ }^{\circ} \mathrm{C}$. The values found are given in table 1 .

Figure 5 shows a plot for the $25^{\circ}$ modulus as a function of the quantity $\mathrm{fp}$. The experimental points are well represented by a linear relation. The slope $\partial G / \partial f p$ and intercept $G_{0}$ were determined by the method of least squares, without using any values obtained from the specimen containing no dicumyl peroxide $(f p=0)$. Similar plots were also made for the other temperatures. The results are given in table 2, together with the standard deviations of each quantity as obtained from the least squares computation.

Figure 6 shows a plot of the slope $\partial G / \partial f p$ as a function of $T$. The experimental points are those given for $\partial G / \partial f p$ in table 2 , and the straight line in figure 6 represents a least squares fit to the points of figure 6 . The relationship appears to be linear within the precision of the observations.

The linearity of the relationships plotted in figures 2 , 3,5 , and 6 permits one to derive by integration a simple expression representing $G$ as a function of $T$ and $f p$. It is

$$
G=S(f p+B) T+H(f p+B)+A
$$

where $A, B, H$, and $S$ are constants and $T$ is expressed in kelvins. We shall find it more convenient to deal with temperatures in kelvins in the remainder of this paper. One can readily note from an examination of this equation that it predicts linearity in the relationships plotted in figures $2,3,5$, and 6 .

The lines represented by the observed slopes and intercepts given in table 2 for the 7 temperatures were now plotted on a graph (not reproduced here) showing $G$ as a function of $f p$ on a greatly expanded scale in the region from $f p=0$ to $f p=1$. It was found that they all intersected near the point where $f p=0.45$ and $G=2.70 \mathrm{Mdyn} \mathrm{cm}^{-2}$. This was verified by using the slopes and intercepts in table 1 to calculate at each temperature the value of $G$ at $f p=0.45$. The results,

TABLE 1. Modulus as a function of cross-linking and temperature

\begin{tabular}{c|c|c|c|c|c|c|c}
\multicolumn{7}{c}{ Temperature ${ }^{\circ} \mathrm{C}$} \\
\hline $\begin{array}{c}f p \\
\mathrm{phr}\end{array}$ & -50 & -25 & 0 & 25 & 50 & 75 & 100 \\
\hline 0 & & & & & & & \\
\hline 0.48 & 3.20 & 3.06 & 2.92 & 2.77 & 2.63 & 2.49 & 2.35 \\
.95 & 3.54 & 3.57 & 3.59 & 3.62 & 3.65 & 3.67 & 3.70 \\
1.90 & 4.85 & 5.01 & 5.16 & 5.32 & 5.47 & 5.63 & 5.78 \\
2.86 & 6.24 & 6.57 & 6.91 & 7.24 & 7.57 & 7.91 & 8.24 \\
3.81 & 7.80 & 8.14 & 8.47 & 8.81 & 9.15 & 9.49 & 9.82 \\
4.76 & 7.60 & 8.37 & 9.14 & 9.91 & 10.68 & 11.45 & 12.22 \\
6.66 & 10.60 & 11.61 & 12.62 & 13.62 & 14.63 & 15.64 & 16.65 \\
7.62 & 12.80 & 13.92 & 15.04 & 16.17 & 17.29 & 18.41 & 19.53 \\
9.52 & 17.30 & 18.20 & 19.00 & 19.90 & 20.80 & 21.60 & 22.50 \\
14.3 & 19.20 & 22.09 & 24.97 & 27.86 & 30.75 & 33.64 & 36.52 \\
19.0 & 29.15 & 32.53 & 35.91 & 39.30 & 42.68 & 46.06 & 49.45 \\
23.8 & 35.90 & 38.50 & 41.10 & 43.70 & 46.30 & 48.90 & 51.50 \\
\hline
\end{tabular}

Modulus values are given in Megadynes per square centimeter $\left(1 \mathrm{Mdyn} \mathrm{cm}^{-2}=0.1 \mathrm{MN} \mathrm{m}^{-2}\right)$. 


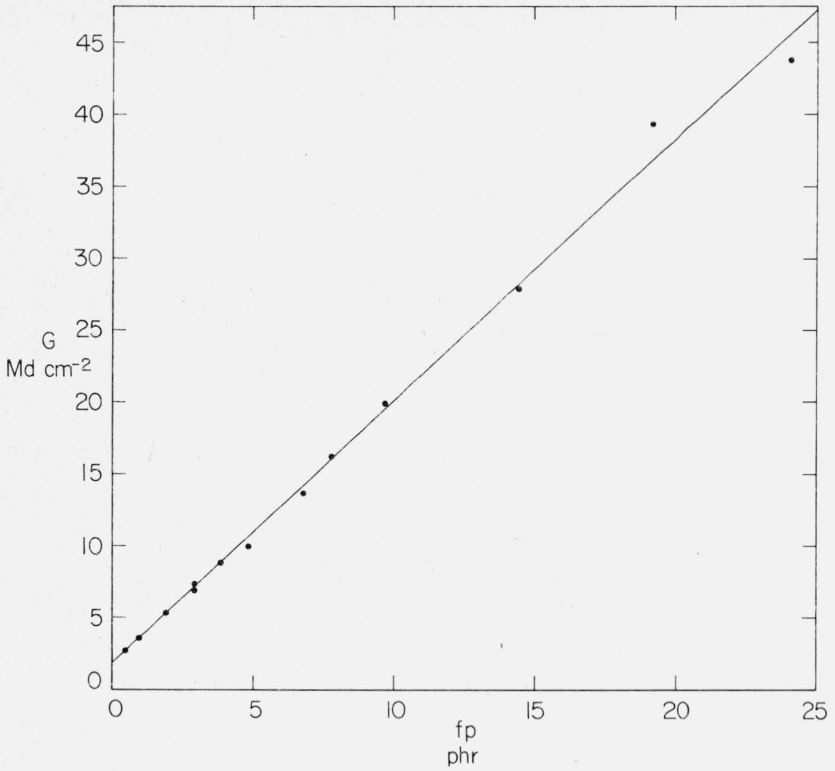

Figure 5. Modulus at $25^{\circ} \mathrm{C}$ as a function of decomposed dicumyl peroxide content.

Experimental points show values read from the straight lines in figures 2 and 3 at $25^{\circ} \mathrm{C}$ The straight line represents the function) $G=1.836 \mathrm{fp}+1.88$ obtained from eq $(6.3)$ at $25^{\circ} \mathrm{C}$.

which are given in the sixth column of table 2 approximate $2.70 \mathrm{Mdyn} \mathrm{cm}^{-2}$ and show no systematic variation with temperature.

This observation that all 7 of the lines like the one in figure 5 , but for different temperatures, pass through a single point permits the evaluation of two of the constants. If the coordinates found for this point are inserted in eq (6.1) we have:

$$
(0.45+B) S T+(0.45+B) H+A=2.70 .
$$

This equation can be yalid at all temperatures if and only if

$$
B=-0.45 \mathrm{phr} \text { and } A=2.70 \mathrm{Mdyn} \mathrm{cm}^{-2} \text {. }
$$

\begin{tabular}{|c|c|c|c|c|c|}
\hline$T^{\circ}{ }^{\circ} \mathrm{C}$ & $\begin{array}{c}\frac{\partial G}{\partial f p} \\
\text { Mdyn } \\
\mathrm{cm}^{-2} \\
\text { phr }^{-1}\end{array}$ & $\begin{array}{l}\text { Std. } \\
\text { Dev. } \\
\text { Mdyn } \\
\mathrm{cm}^{-2} \\
\text { phr }^{-1}\end{array}$ & $\begin{array}{c}G_{0} \\
\text { Mdyn } \\
\mathrm{cm}^{-2}\end{array}$ & $\begin{array}{l}\text { Std. } \\
\text { Dev. } \\
\text { Mdyn } \\
\mathrm{cm}^{-2}\end{array}$ & $\begin{array}{c}G \text { at } \\
f p=0.45 \\
\text { Mdyn } \\
\mathrm{cm}^{-2}\end{array}$ \\
\hline-50 & 1.393 & 0.048 & 2.07 & 0.52 & 2.70 \\
\hline-25 & 1.535 & .038 & 2.06 & .41 & 2.75 \\
\hline 0 & 1.686 & .035 & 1.96 & .38 & 2.72 \\
\hline 25 & 1.836 & .042 & 1.88 & .44 & 2.71 \\
\hline 50 & 1.986 & .054 & 1.80 & .58 & 2.69 \\
\hline 75 & 2.131 & .066 & 1.75 & .71 & 2.71 \\
\hline 100 & 2.278 & .085 & 1.70 & .92 & 2.72 \\
\hline
\end{tabular}

The derivative of eq (6.1)

Note: 1 Mdỵn $\mathrm{cm}^{-2}=0.1 \mathrm{MN} \mathrm{m}^{-2}$.

$$
\partial G / \partial f p=S T+H
$$

showing that linearity should be expected in the increasing function plotted in figure 6 , permits the evaluation of the other two constants from the slope and intercept of this line of positive slope.

The least squares computation in this case gives the slope $S=(5.925 \pm 0.018) \times 10^{-3} \quad$ Mdyn $\quad \mathrm{cm}^{-2}$ $\mathrm{K}^{-1}(\mathrm{phr})^{-1}$ and the intercept at $0 \mathrm{~K}, H=0.0684$ \pm 0.0055 Mdyn $\mathrm{cm}^{-2}(\mathrm{phr})^{-1}$.

Thus eq (6.1) becomes

$$
\begin{aligned}
G=5.925 \times 10^{-3}( & f p-0.45) T \\
& +0.0684(f p-0.45)+2.70
\end{aligned}
$$

where $G$ is in Mdyn $\mathrm{cm}^{-2}, T$ in kelvins, and $f p$ in phr. This single equation with its four constants empirically determined represents satisfactorily all the data for modulus obtained in the present work. The lower limit of the temperature range covered was set by the occurrence of phenomena related to the glass transition and the upper limit was set at $373.15 \mathrm{~K}$ $\left(100^{\circ} \mathrm{C}\right.$ ) because of possible degradation at higher temperatures.

The data at low values of $f p$, where there was appreciable creep, were somewhat less reliable than those where there was no creep, but did not deviate systematically from the expected values obtained by extrapolation downward from the region where $f p$ was large. The dashed straight line shown in figure 2 corresponding to $f p=0$ was drawn to pass through the extrapolated value of $G=1.88 \mathrm{Mdyn} \mathrm{cm}^{-2^{\prime}}$ at $25^{\circ}$, as already stated, but was not used in determining any of the constants.

$G_{0}$ the intercept at $f_{p}=0$, is obtained from eq (6.1) as

$$
G_{0}=S B T+H B+A=-2.63 \times 10^{-3} T+2.67 .
$$

Figure 6 shows a line of negative slope corresponding to this equation for comparison with the experimental values of $G_{0}$ taken from table 2 (fourth column), obtained by least squares from data like that of figure 5 . If eq (6.1) is differentiated with respect to temperature one obtains

$$
\begin{aligned}
\partial G / \partial T=S f p+S B=5.925 \times 10^{-3} f p & \\
& -2.67 \times 10^{-3} .
\end{aligned}
$$

This relationship is shown in figure 7 where the line corresponding to the equation can be compared with the experimental points taken directly as the slopes of the straight lines in figures 2 and 3 .

\section{Comparison With Results of Other Observers}

The values of modulus previously found over more limited ranges of variables by other methods of measurement are in general agreement with those reported here. Figure 8 shows a graph of the 10 -min modulus at 


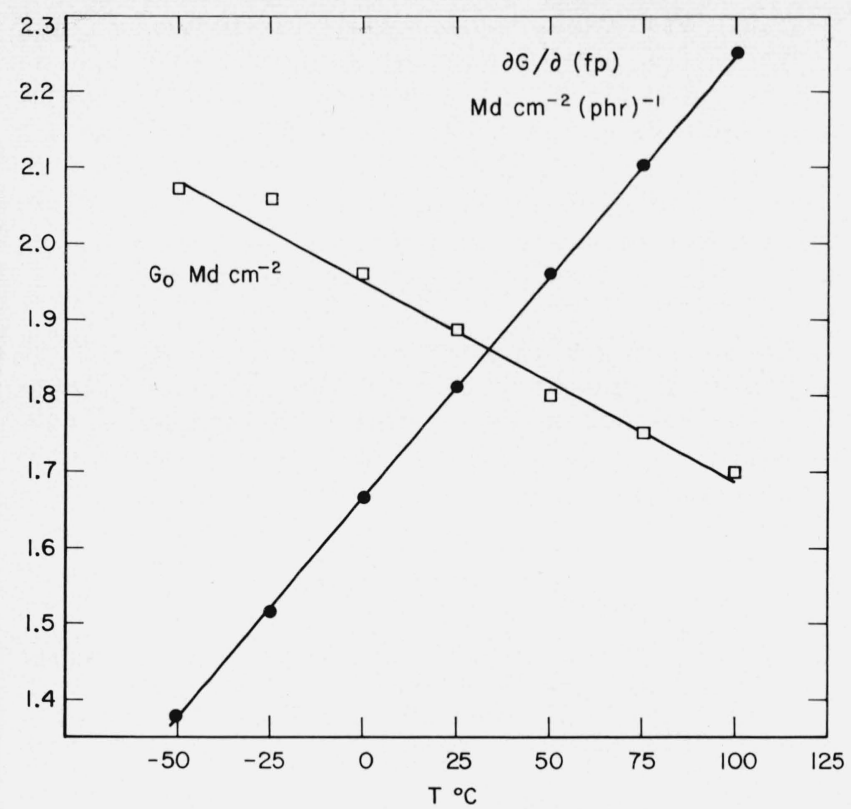

FIGURE 6. Rate of increase of modulus with increase of decomposed dicumyl peroxide content as a function of temperature.

- Data from table 2, column 2

Modulus for no added dicumyl peroxide as a function of temperature Data from table 2, column 4

$30^{\circ}$ over the lower range of values of $f p$. The straight line shown has the slope $1.864 \mathrm{Mdyn} \mathrm{cm}^{-2}$ per unit of $f p$ and the intercept $G_{0}=1.86 \mathrm{Mdyn} \mathrm{cm}^{-2}$, as calculated from eq $(6.3)$ at $30{ }^{\circ} \mathrm{C}(303.15 \mathrm{~K})$. The experimental points from the present work were read directly from the straight lines of figure 2 at $30^{\circ}$.

Figure 8 also shows the results obtained by Chasset and Thirion [17] of the Institut Français du Caoutchouc who measured the stress at $30^{\circ}$ in samples elongated 50 percent. The numerical values plotted here are given in tabular form in our earlier paper [3] devoted to creep. In their work specimens of

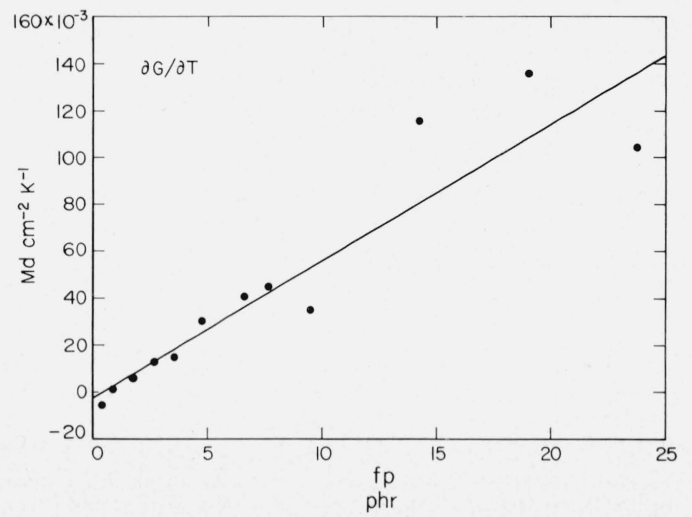

FiguRE 7. Rate of increase of modulus with increase of temperature as a function of decomposed dicumyl peroxide content.

- Slopes of the lines in figures 2 and 3 .

The straight line represents eq $(6.5), \partial G / \partial T=5.925 \times 10^{-3} f p-2.67 \times 10^{-3}$

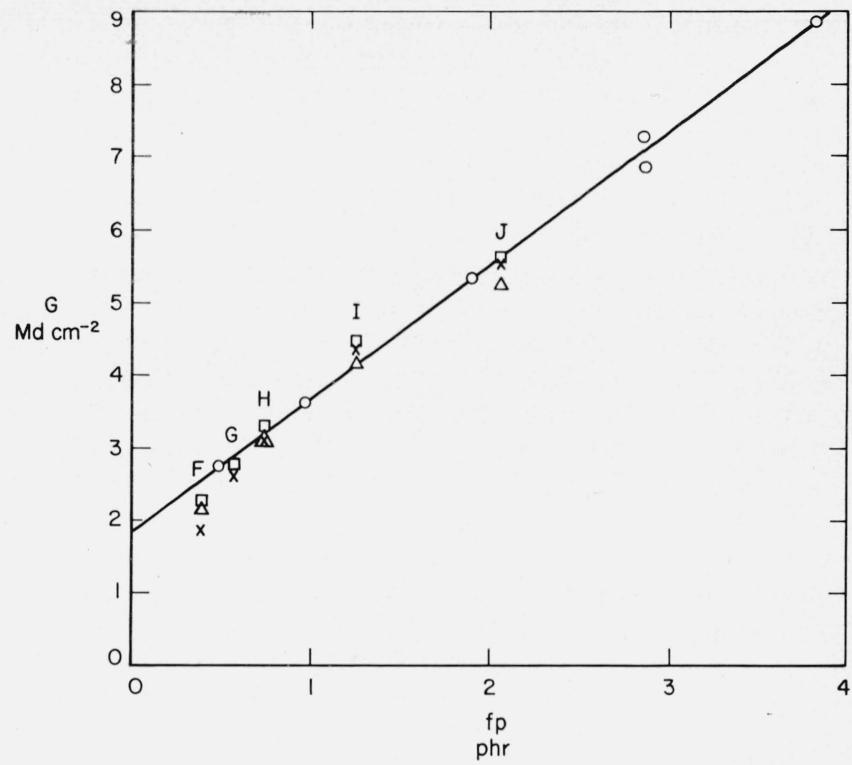

Figure 8. Modulus at $30^{\circ} \mathrm{C}$ as a function of decomposed dicumyl peroxide content.

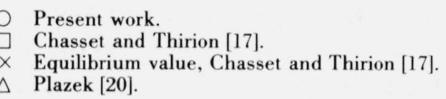

The straight line represents the function $G=1.864 f p+1.86$ obtained from eq (6.3) at $30^{\circ} \mathrm{C}$.

natural rubber containing 3.5 parts of dicumyl peroxide per hundred of rubber were cured $20,30,40,75$, and $150 \mathrm{~min}$ at $135^{\circ} \mathrm{C}$ and designated as F, G, H, I, and J respectively.-The half-life at this temperature according to eq (1.3) using Hummel's constants, is 117.5 min. The value of $f$ obtained from eq (1.1) for each specimen was multiplied by 3.5 and used as the abscissa in figure 8. The ordinates were computed from the stress at 50 percent elongation after $10 \mathrm{~min}$ of stress relaxation at $30^{\circ}$ as reported by Chasset and Thirion. The ratio of $F_{50}$, the stress at 50 percent elongation to $M$, Young's Modulus, was taken from the empirical equation of Martin, Roth, and Stiehler [18] as $F_{50} / M=$ 0.3050 . Thus the shear modulus $G$ was computed as 1.093 times the stress reported.

The value of $F_{50} / M=\frac{1}{3}\left(L_{50}-L_{50}^{-2}\right)=0.3519$

(where $L_{50}=1.50$, the ratio of stressed length to unstressed length), given by the simple statistical theory of rubber elasticity was not used, since it gives, at 50 percent elongation, modulus values about 15.5 percent lower than those actually observed [19].

Chasset and Thirion [17] developed a relationship for calculating an equilibrium stress obtained by extrapolation to infinite time. Values of the transient term given by this relationship at $10 \mathrm{~min}$ can be read from figure 4 of their paper. The difference between the 10 -min modulus and the equilibrium modulus is thus found to be $18,9.6,5.4,2.5$ and 1.2 percent of 
the equilibrium modulus for the Specimens F, G, H, $I$, and $J$ respectively. Equilibrium modulus values and 10-min modulus values are both plotted in our figure 8. The difference between the two is considered to be negligible for values of $f p$ greater than $2 \mathrm{phr}$.

Duplicates of specimens $\mathrm{F}, \mathrm{H}, \mathrm{I}$, and $\mathrm{J}$ were furnished by Thirion to D. J. Plazek of Mellon Institute who measured [20] the shear modulus with a torsion pendulum at very low deformations. The 10-min moduli at $30^{\circ}$ (as read from the compliances shown in figure 2 of Plazek's paper) are also plotted as ordinates in our figure 8 . The values of Chasset and Thirion together with those of Plazek are likewise plotted at $30^{\circ}$ in our figure 2 .

All three sets of observations, in which the moduli were measured by widely different techniques on specimens prepared under different conditions are represented in a highly satisfactory fashion by the line shown. The creep calculated from the observations of Chasset and Thirion and of Plazek was also in good agreement with the present studies at comparable degrees of cross-linking [3, 4].

The data of Chasset and Thirion and of Plazek, just discussed, were confirmed by similar results on duplicates of these specimens investigated in Ferry's laboratory at the University of Wisconsin $[21,22]$. On the whole, these results appear to be better suited than other literature studies to be subjected to a direct comparison with those of the present work. An examination of several other investigations also permits the calculation of values of $G$ in general agreement with our own.

\section{Summary and Conclusions}

The modulus $G$ of natural rubber cross-linked with varying amounts of dicumyl peroxide has been calculated from indentation measurements. A fraction $f$, of the number of parts $p$, of dicumyl peroxide added per hundred parts of rubber is decomposed during the time of cure and thereby rendered effective for cross-linking. The results obtained are represented by the general relation.

$$
G=S(f p+B) T+H(f p+B)+A
$$

where $T$ is the temperature in kelvins and $A, B, H$, and $S$ are constants with the following values:

$$
\begin{aligned}
& A=2.70 \text { Mdyn } \mathrm{cm}^{-2} \\
& B=-0.45 \mathrm{phr} \\
& S=5.925 \times 10^{-3} \mathrm{Mdyn} \mathrm{cm}^{-2}(\mathrm{phr})^{-1} \mathrm{~K}^{-1} \text { and }
\end{aligned}
$$

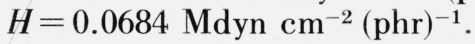

The equation represents the data obtained in the range of temperature from -50 to $+100{ }^{\circ} \mathrm{C}$ for values of $f p$ from about 1 to $24 \mathrm{phr}$. It can be readily noted that the modulus is $2.70 \mathrm{Mdyn} \mathrm{cm}^{-2}$ when $f p=0.45$ for all values of temperature.

The glass transition, manifesting itself as a discontinuity in the slope of the modulus-temperature relation, was found to be raised by about $1.2^{\circ}$ for each part $f p$ of decomposed dicumyl peroxide.

The thermodynamic consequences and molecular interpretation of these experimental results together with a comparison with the predictions of the simplest form of statistical theory of rubber elasticity, will be the subject of a second paper in this series.

The authors acknowledge with thanks the assistance of Albert M. Brown of the Product Evaluation Technology Division of the Institute of Applied Technology, who made several of the experimental observations reported here.

\section{References}

[1] Wood, L. A., and Roth, F. L., Creep of pure-gum rubber vulcanizates from indentation-time measurements, Proc. 4th Rubber Technol. Conf., London 1962, p. 328; Institution of Rubber Industry, London, 1963, Rubber Chem. Technol. 36, 611 (1963).

[2] Roth, F. L., Bullman, G. W., and Wood, L. A., Compliancetime-temperature relationships from indentation measurements on a pure-gum rubber vulcanizate, J. Res. Nat. Bur. Stand. 69A, 347 (1965); Rubber Chem. Technol. 39, 397 (1966).

[3] Wood, Lawrence A., Creep of pure-gum vulcanizates of natural rubber, J. Rubber Res. Inst. Malaya 22, (3), 309 (1969); Rubber Chem. Technol. 43, 1482 (1970).

[4] Wood, Lawrence A. and Bullman, George W., Creep and other tensile properties of rubber cross-linked by dicumyl peroxide, J. Polymer Sci. A-2, 10, (1972).

[5] Loan, L. D., Mechanism of the peroxide vulcanization of elastomers, Rubber Chem. Technol. 40, 149 (1967).

[6] Hummel, K., Scheele, W., and Hillmer, K. H., Vulcanization of natural rubber by dicumyl peroxide in the absence of additives, Kautschuk Gummi 14, (6), WT 171 (1961).

[7] Hertz, H., J. Math. (Crelle's J.) 92, 156 (1881), Gesammelte Werke, Vol. 1, p. 155 and 174, Barth. Leipzig 1895; Miscellaneous Papers, Translated into English by D. E. Jones and G. A. Schott, p. 146 and 163, MacMillan, London, 1896.

[8] Timoshenko, S. and Goodier, F. N., Theory of Elasticity, 3rd Edition, p. 412 (McGraw Hill, New York, 1970).

[9] Larrick, L., The hardness of rubber and other highly elastic materials, Abstract, Phys. Rev. 57, 358 (1940); The standardization of durometers, Rubber Chem. Technol. 13, 969 (1940).

[10] Gent, A. N., On the relation between indentation hardness and Young's Modulus, Trans. Inst. Rubber Ind. 34, 46 (1958); Rubber Chem. Technol. 31, 896 (1958).

[11] Scott, J. R., Rubber hardness testing, Rubber Age (N.Y.) 77, 543 (1955); Rubber Chem. Technol. 28, 1071 (1955).

[12] Waters, N. E., The indentation of thin rubber sheets by spherical indentors, Brit. J. Applied Phys. 16, 557 (1966).

[13] Waters, N. E., Variation of indentation hardness with sample thickness, J. Inst. Rubber Ind. 43, 51 (1967).

[14] Meyer, Kurt H. and Ferri, Cesare, The elasticity of rubber, Helvetica Chim. Acta 18, 570 (1935); Rubber Chem. Technol. 8, 319 (1935).

[15] Witte, Robert S. and Anthony, Robert L., Stress-temperature studies of transitions in rubbers, J. Applied Phys. 22, 689 (1951); Rubber Chem. Technol. 25, 468 (1952).

[16] Mason, P., Thermal expansion and viscoelasticity of rubber in relation to cross-linking and molecular packing, Polymer 5, 625 (1964); Rubber Chem. Technol. 39, 408 (1966).

[17] Chasset, R. and Thirion, P., Viscoelastic relaxation of rubber vulcanizates between the glass transition and equilibrium, Proc. Int. Conf. Non-Crystalline Solids, Delft 1964, J. A. Prins, Ed., p. 345, North-Holland Publishing Co., Amsterdam, Interscience Publishers, New York; Rubber Chem. Technol. 39, 870 (1966); Rev. Gen. Caoutchouc 44, 1041 (1967). 
[18] Martin, G. M., Roth, F. L., and Stiehler, R. D., Behavior of pure-gum rubber vulcanizates in tension, Trans. Inst. Rubber Industry 32, (6), 189 (1956); Rubber Chem. Technol. 30, 876 (1957).

[19] Wood, Lawrence A., Stress-strain relation of pure-gum rubber vulcanizates in compression and tension, J. Research Nat. - Bur. Standards 60, 193 (1958); Rubber Chem. Technol. 32, 1 (1959).

[20] Plazek, D. J., Effect of cross-link density on the creep behavior of natural rubber vulcanizates, J. Polymer Sci. A-2, 4, 745 (1966).
[21] Ferry, John D., Mancke, Ralph G., Maekawa, Etsuji, Oyanagi, Yasuji, and Dickie, Ralph A. Dynamic mechanical properties of cross-linked rubber. I. Effects of cross-link spacing in natural rubber. J. Phys. Chem. 63, 3414 (1964) Rubber Chem. Technol. 39, 897 (1966).

[22] Dickie, R. A., and Ferry, John D. Mechanical properties of substances of high molecular weight. L. Dynamic mechanical properties of cross-linked rubbers. III. Dicumyl peroxide vulcanizates of natural rubber. J. Phys. Chem. 70, 2594 (1966).

(Paper 76Al-698) 